\title{
Napak Tilas Pancasila dalam Sejarah Perjuangan Bangsa Indonesia: Kajian Pustaka
}

\author{
Susilawati* \\ Instansi BPSDM Provinsi Jambi \\ J1 H. agus Salim No 19 Kota Baru Telp (0741) 41124, 42170 \\ *Correspondence email: natsirsusilawati81@gmail.com
}

\begin{abstract}
Abstrak. Bangsa Indonesia dapat dinyatakan sebagai kausa materialis Pancasila karena nilai-nilai essensial yang terkandung dalam Pancasila yaitu: Ketuhananan, Kemanusiaan, Persatuan, Kerakyatan dan keadilan secara ojektif telah dimiliki oleh Bangsa Indonesia sejak zaman dahulu kala sebelum nendirikan negara. Nilai-nilai tersebut kemudian diangkat dan dirumuskan secara formal oleh para pendiri negara untuk dijadikan sebagai dasar filsafat negara Indonesia. Oleh karena itu pmahaman Pancasila harus dilakukan secara utuh dalam kaitannya dengan jati diri Bangsa Indonesia. Hal ini merupakan hal yang sangat urgen agar tidak terjadi penyimpangan dalam perjalanan waktu dan pergantian era pemerintahan.
\end{abstract}

Kata kunci: Pancasila; causa materialis; dasar filsafat Negara Indonesia

Abstract. The Indonesian nation can be stated as the material cause of Pancasila because the essential values contained in Pancasila, namely: Divinity, Humanity, Unity, Population and justice objectively have been owned by the Indonesian nation since ancient times before the founding of the state. These values were then formally adopted and formulated by the founders of the state to serve as the basis for the philosophy of the Indonesian state. Therefore, the understanding of Pancasila must be carried out in its entirety in relation to the identity of the Indonesian Nation. This is very urgent so that there are no deviations in the course of time and the change in the era of government.

Keywords: Pancasila; causa materialis; basic philosophy of Indonesian State.

\section{PENDAHULUAN}

Pancasila telah tumbuh sejalan dengan perkembangan Bangsa Indonesia. Pancasila telah bersifat final sebagai dasar negara bagi bangsa Indonesia pada Negara Kesatuan Republik Indonesia. dan diterima secara luas oleh masyarakat sebagai warga negara Republik Indonesia. Penetapan Pancasila sebagai dasar negara sangat diperlukan oleh Bangsa Indonesia, karena Bangsa Indonesia merupakan bangsa yang memiliki keberagaman yang tinggi (Syarbaini, 2006).

Menetapkan Pancasila sebagai dasar negara semakin memantapkan Pancasila sebagai alat pemersatu yang memandang keberagaman bangsa dalam segala bidang kehidupan bukan awal perpecahan tetapi merupakan aset dan kekuatan bangsa dan negara. Dengan demikian, penyelenggaraan pemerintahan akan diatur oleh Pancasila. Konsekwensi logisnya menurut Daulay (2007), adalah sumber dari segala sumber hukum negara adalah Pancasila. Oleh karena itu semua peraturan perundang-undangan yang berlaku harus bmengandung dan melaksanakan nilai-nilai Pancasila.

\section{METODE}

Adapun metode penelitian kajian pustaka atau studi kepustakaan yaitu berisi teori teori yang relevan dengan masalah - masalah penelitian. Adapun masalah pada penelitian ini adalah untuk mengetahui "Napak Tilas Pancasila dalam Sejarah Perjuangan Bangsa Indonesia". Pada bagian ini dilakukan pengkajian mengenai konsep dan teori yang digunakan berdasarkan literatur yang tersedia, terutama dari artikel-artikel yang dipublikasikan dalam berbagai jurnal ilmiah. Kajian pustaka berfungsi untuk membangun konsep atau teori yang menjadi dasar studi dalam penelitian. (Sujarweni, 2014)

\section{HASIL DAN PEMBAHASAN \\ Napak Tilas Pancasila \\ Pancasila Dalam Era Pra Kemerdekaan}

Perjalanan sejarah Bangsa Indonesia pada abad ke 7 menunjukkan fakta yang menarik untuk dikaji. Kerajaan Samudera Pasai, Sriwijaya, Demak, Mataram Majapahit, Kutai, Singosari dan lain-lain memiliki jiwa dan kepribadian yang sama, walaupun kadang-kadang tidak tertutup kemungkinan untuk terjadinya konflik (Syarbaini, 2006). Kesamaan jiwa dan kepribadian tersebut dijaga selama berabad-abad untuk mempertahankan eksistensi mereka.

Kedatangan penjajah pada pertengahan Abad ke16 dengan segala aktivitasnya membuat bangkitnya semangat kebersamaan. Semangat kebersamaan tidak bisa dibendung, akhirnya 28 Oktober 1928 menjadi tonggak sejarah dengan lahirnya sumpah pemuda. Semangat kebersamaan ini diawali dengan lahirnya Budi Utomo pada 20 Mei 1908. Kelahiran Budi Utomo menjadi simbol kebangkitan nasional Bangsa Indonesia. Menurut Syarbaini (2006) dan Katimin (2010), tonggak sejarah ini melahirkan Sumpah Pemuda sebagai refleksi 
rasa nasionalisme yang kuat dan dinamika kehidupan bangsa yang dinamis berbasis nilai-nilai Pancasila melalui 3 pernyataan sikap:

\section{"Kami putra putri Indonesia}

Mengaku bertumpah darah yang satu, tanah air Indonesia; Mengaku berbangsa yang satu, bangsa Indonesia;

Menjunjung bahasa persatuan, bahasa Indonesia."

Pancasila terdapat dalam wujud dalam nilai, kebiasaan, adat, agama, watak dan perangai pada setiap jiwa Bangsa Indonesia. Oleh karena itu Pancasila bukan hal baru, tetapi digali dan dirumuskan kembali. Kesepakatan Bangsa Indonesia, menetapkan 1 Juni sebagai hari lahirnya Pancasila.

Proses pengesahan UUD 1945 dilakukan pada Tanggal 18 Agustus 1945 merupakan momentum penting bagi Bangsa dan Negara Indonesia, karena pada saat itu merupakan momentum penetapan Pancasila sebagai dasar negara. Proses pengesahan ini akhirnya disepakati dengan meniadakan rumusan 7 kata "dengan kewajiban menjalankan suariat Islam bagi pemelukpemeluknya" sebagai produk Piagam Jakarta. Peniadaan 7 kata ini berawal dari respon kurang sepakat dari golongan non muslim dan bermuara pada kerelaan golongan muslim demi kepentingan nasional (Maryani, 2014).

\section{Pancasila Dalam Era Kemerdekaan}

Banyak terjadi perkembangan setelah Indonesia memproklamirkan kemerdekaannya. Menurut pantauan sejarah, pada masa itu Pancasila mengalami masa kejayaannya, karena pada masa itu merupakan masamasa percobaan berdemokrasi. Pancasila mendapat ujian berat dan mengalami masa suram pada akhir Tahun 1959, saat Presiden Soekarno menerapkan sistem Demokrasi Terpimpin.

Sejarah lahirnya Pancasila tidak dapat dipungkiri, berkaitan dengan BPUPKI (Badan Penyelidik UsahaUsaha Persiapan Kemerdekaan Indonesia). Menurut Taufik, 2013), sejarah mencatat Tanggal 1 Maret 1945 sebagai momentum penting dalam perjalanan sejarah Bangsa Indonesia dengan dibentuknya BPUPKI oleh Pemerintah Jepang. Pembentukan BPUKI bertujuan untuk mempelajari hal-hal yang berhubungan dengan tata pemerintahan Indonesia merdeka. Pembentukan BPUKI ini merupakan perwujudan janji Perdana Menteri Jepang saat itu, Kuniaki Koiso pada tanggal 7 September 1944, yang akan memberikan kemerdekaan kepada Bangsa Indonesia.

BPUKI membentuk Panitia 9 yang dipimpin oleh Ir. Soekarno. Dalam aktivitasnya, Panitia 9 selain menampung usulan perorangan untuk merumuskan dasar negara, juga berhasil merumuskan Rancangan Mukaddimah Hukum Dasar yang dinamakan Piagam Jakarta Tanggal 22 Juni 1945. Dalam Piagam Jakarta, sila pertama berbunyi: "Ketuhanan dengan kewajiban menjalankan syariat Islam bagi pemeluk-pemeluknya".
Hal inilah yang membuat berberapa utusan dari wilayah Indonesia Bagian Timur menyatakan keberatannya. Keberatan itu dinyatakan pada saat mereka mendatangi BPUKI setelah upacara Proklamasi Kemerdekaan 17 Agustus 1945 (Maryani, 2014). Utusan tersebut adalah: (1) Sam Ratulangi wakil dari Sulawesi, (2) Tadjoedin Noor dan (3) Ir. Pangeran Noor wakil dari Kalimantan, (4) I Ketut Pudja wakil dari Nusa Tenggara dan (5) Latu Harhary wakil dari Maluku (Taufik 2013).

Sejarah juga mencatat bahwa BPUPKI (Badan Penyelidik Usaha-Usaha Persiapan Kemerdekaan Indonesia) yang akhirnya berubah nama menjadi PPKI (Panitia Prsiapan Kemerdekaan Indonesia). Untuk mengakomodir keberatan yang diajukan oleh utusan dari Wilayah Indonesia Bagian Timur tersebut menurut Taufik (2013), maka Muhammad Hatta lalu mengusulkan mengubah tujuh kata tersebut menjadi "Ketuhanan Yang Maha Esa". Pengusulan itu dilakukan pada Sidang PPKI Pertama tanggal 18 Agustus 1945. Pengubahan kalimat ini telah dibicarakan dengan tokoh Islam, demi persatuan dan kesatuan bangsa. Tokoh Islam yang dimaksud adalah Kasman Singodimejo, Wahid Hasyim, Ki Bagus Hadikusumo, dan Teuku M. Hasan. Pada Sidang PPKI Pertama tanggal 18 Agustus 1945, ditetapkan Rancangan Pembukaan dan Batang Tubuh UUD 1945 sekaligus penetapan Pancasila sebagai Dasar Negara Indonesia.

\section{Pancasila Dalam Era Orde Lama}

Dalam sistem kenegaraan, maka Orde Lama bagi Bangsa Indonesia adalah masa pencarian bentuk implementasi Pancasila. Hal ini terlihat dari pengimplementasian Pancasila dalam bentuk yang berbeda-beda. Sejarah mencatat, ada 3 periode implementasi Pancasila yang berbeda, yaitu periode 1945-1950, periode 1950-1959, dan periode 1959-1966 (Syarbaini, 2003). Hal ini sangat dimungkinkan karena kondisi tajamnya konflik ideologi, kacaunya politik dan keamanan dalam negeri serta kondisi sosial budaya yang berada dalam suasana transisional. Transisional dari masyarakat terjajah menjadi masyarakat merdeka.

Periode 1945 - 1950 ditandai oleh upaya-upaya mengganti Pancasila sebagai dasar negara. Di satu pihak, PKI melakukan pemberontakan di Madiun Tahun 1948 dan melakukan upaya untuk mengganti Pancasila dengan faham komunis. Di pihak lain, DI/TII juga melakukan upaya untuk mendirikan negara dengan dasar Islam. Hal yang menguntungkan pada periode ini adalah masih tingginya nilai persatuan dan kesatuan ketika menghadapi Belanda yang masih ingin mempertahankan penjajahannya di bumi Indonesia (Maryani, 2014). Nilai persatuan mendapat tantangan yang cukup hebat setelah penjajah dapat diusir. Demokrasi yang diterapkan adalah Demokrasi Parlementer. Presiden berfungsi sebagai Kepala Negara dan Perdana Menteri sebagai Kepala Pemerintahan. Akibatnya secara politik, sila keempat yang mengutamakan musyawarah dan mufakat tidak 
dapat dilaksanakan, tidak adanya stabilitas pemerintahan. Dengan demikian, walaupun dasar negara yang digunakan adalah Pancasila dan konstitusi yang digunakan adalah UUD 1945, tetapi dalam prakteknya kenegaraan sistim presidensiil tak dapat diwujudkan.

Periode 1950 -1959 Pancasila diarahkan sebagai ideologi liberal (Taufik, 2013) . Sistem pemerintahan yang liberal lebih menekankan hak-hak individual ternyata tidak menjamin stabilitas pemerintahan. Walaupun dasar negara tetap Pancasila, tetapi rumusan sila keempat bukan berjiwakan musyawarah mufakat, melainkan suara terbanyak (vooting). Munculnya pemberontakan RMS, PRRI, dan Permesta yang ingin melepaskan diri dari NKRI, membuat persatuan dan kesatuan mendapat tantangan yang berat. Terjadi krisis politik, ekonomi, dan keamanan, karena anggota Konstituante hasil pemilu tidak dapat menyusun UUD seperti yang diharapkan. Akhirnya, pemerintah mengeluarkan Dekrit Presiden 1959 untuk membubarkan Konstituante, menyatakan UUD 1950 tidak berlaku, dan kembali kepada UUD 1945.

Periode 1956-1965, merupakan masa suramnya perjalanan Pancasila dalam sejarah Bangsa Indonesia. Periode ini juga dikenal dengan dikenal sebagai periode Demokrasi Terpimpin (Syarbaini, 2003). Demokrasi berada pada kekuasaan pribadi Presiden Soekarno bukan berada pada kekuasaan rakyat. Kondisi ini memungkinkan terjadinya berbagai penyimpangan penafsiran terhadap Pancasila dalam konstitusi. Beberapa wujud nyata yang dilihat dari berbagai penyimpangan tersebut adalah otoriternya Soekarno, mengangkat Soekarno menjadi presiden seumur hidup, politik konfrontasi, menggabungkan Nasionalis, Agama, dan Komunis, yang ternyata tidak cocok bagi NKRI dan lain-lain.

Akibat penyimpangan tersebut, terjadi kemerosotan moral di sebagian masyarakat yang tidak lagi hidup bersendikan nilai-nilai Pancasila, dan berusaha untuk menggantikan Pancasila dengan ideologi lain. Presiden sebagai pemegang kekuasaan tertinggi, menekankan pentingnya memegang teguh UUD 45, sosialisme ala Indonesia, demokrasi terpimpin, ekonomi terpimpin dan kepribadian nasional. Kondisi ini bermuara pada kudeta PKI dan kondisi ekonomi yang memprihatinkan.

\section{Pancasila Dalam Era Orde Baru \\ a. Masa Transisi}

Menurut Daulay (2007), Masa Transisi adalah rentang waktu antara Tahun 1966 - 1967. Periode ini dinamakan sebagai masa transisi karena terdapat dualisme kepemimpinan anatar Presiden Soekarno dan Jenderal Soeharto. Soekarno masih aktif sebagai Presiden, sedangkan Jenderal Soeharto berhasil menumpas pemberontakan PKI dalam waktu singkat dan melaksanakan Surat Perintah 11 Maret 1966 dalam usaha-usaha stabilisasi politik dan ekonomi.
Dualisme berakhir pada saat MPRS mengeluarkan Ketetapan MPRS No. IX/MPRS/1966 di Jakarta, 20 Februari 1966 (Thohir, 2009). Sejak saat itu terjadi penyerahan kekuasaan dari Presiden Soekarno kepada Jenderal Soeharto. Tahun 1968 adalah masa konsolidasi. Pemerintah dan DPR-GR berupaya menyelesaikan perselisihan antara kaum pribumi dan non-pribumi, menyelesaikan masalah korupsi serta menyelesaikan berbagai macam undang-undang yang sangat mendesak dan diperlukan. Tahun 1971, aktivitas lebih banyak dicurahkan kepada kegiatan kampanye menghadapi pemilihan umum yang pertama pada jaman Orde Baru serta pemilihan umum yang kedua dalam sejarah Republik Indonesia.

\section{b. Era Orde Baru}

Pancasila dan UUD 1945 dipandang sebagai sesuatu yang keramat sehingga tidak boleh diganggu gugat menurut Pemerintah Orde Baru. Pemerintah Orde Baru bertekad untuk melaksanakan Pancasila dan UUD 1945 secara murni dan konsekuen. Namun kenyataannya, Pancasila tetap pada posisinya sebagai alat pembenar rezim otoritarian di bawah Soeharto. Pancasila sebagai ideologi terbuka, serta UUD 1945 sebagai landasan konstitusi, penafsiran dan implementasinya berada di tangan negara.

Menurut Sulistyo (2020), Pemerintah Orde Baru tidak hanya monopoli kekuasaan, tetapi juga memonopoli kebenaran. Bila terdapat sikap politik masyarakat yang kritis dan berbeda dengan negara dalam prakteknya, diperlakukan sebagai pelaku tindak kriminal atau subversif. Hal ini dapat dirasakan dari penyeragaman pemikiran Bangsa Indonesia yang sangat plural, sehingga gagasan mengenai pluralisme tidak mendapat tempat untuk didiskusikan secara intensif. Puncaknya, seluruh organisasi sosial politik pada tahun 1985, digiring oleh hukum untuk menerima Pancasila sebagai asas tunggal. Setiap warga negara yang mengabaikan Pancasila atau setiap organisasi sosial yang menolak Pancasila sebagai asas tunggal akan memperoleh cap sebagai pengkhianat atau penghasut. Periode ini disebut juga demokrasi Pancasila.

Pemerintah Orde Baru melakukan pengkultusan terhadap Pancasila dengan menetapkan Hari Kesaktian Pancasila Tanggal setiap 1 Oktober, sebagai bukti kemampuan menumpas G30S/PKI. Pemerintah Orde Baru juga mensosialisasikan nilainilai Pancasila melalui TAP MPR NO II/MPR/1978 tentang pedoman penghayatan dan pengamalan Pancasila (p4) di sekolah dan masyarakat. Menurut Pemerintah Orde Baru diperlukan pemahaman yang sama tentang Demokrasi Pancasila (Sulistyo, 2020). Dengan pemahaman yang sama, diharapkan persatuan dan kesatuan nasional akan terbentuk dan terpelihara. Akibatnya diwajibkan melakukan penataran terhadap Siswa, mahasiswa, organisasi 
sosial, dan lembaga-lembaga negara. Dengan kegiatan tersebut, diharapkan opini rakyat akan mengarah pada dukungan yang kuat terhadap pemerintah Orde Baru.

Pancasila dipandang oleh Pemerintah Orde Baru sebagai doktrin yang komperehensif. Pandangan ini dapat terlihat dari anggapan bahwa ideologi sebagai sumber nilai dan norma, akibatnya harus ditangani melalui upaya indoktrinasi secara terpusat. Menurut Sulistyo (2020), pandangan ini akan berujung pada perfeksionisme negara. Bila ini terjadi, maka akan muncul negara perfeksonis.. Negara perfeksionis adalah negara yang merasa tahu apa yang benar dan apa yang salah bagi masyarakatnya. Sesuatu yang dianggap benar kalau hal tersebut sesuai dengan keinginan penguasa, sebaliknya sesuatu dianggap salah kalau bertentangan dengan kehendak penguasa.

\section{Era Reformasi}

Gerakan reformasi yang dilakukan oleh Bangsa Indonesia ditandai dengan diangkatnya Prof. Dr. B.J Habibie sebagai Presiden menggantikan Soeharto pada Tanggal 21 Mei 1998 (Amir, 2003). Gerakan reformasi merupakan gerakan moral politik yang menuntut adanya reformasi di segala bidang terutama bidang hukum, politik, ekonomi, dan pembangunan yang dilakukan oleh masyarakat dan dipelopori oleh mahasiswa, cendekiawan dan masyarakat dari berbagai lapisan. Munculnya gerakan reformasi ini untuk membenahi klimaks dari penyimpangan terhadap Pancasila yang berwujud hancurnya perekonomian nasional (Syarbaini, 2003). Semua tindakan dan kebijakan mengatasnamakan Pancasila, walaupun ada kenyataannya tindakan dan kebijakan tersebut sangat bertentangan dengan Pancasila. Hal ini dilakukan mengingat Pancasila diyakini sebagai sumber nilai, dasar moral etik bagi negara dan aparat pelaksana negara sehingga digunakan sebagai alat legitimasi politik.

Kenyataan yang dihadapi, menunjukkan bahwa sebagian masyarakat salah dalam memahami arti kata reformasi. Hal ini terlihat dari perusakan beberapa fasilitas umum yang diawali oleh aksi anarkhis akibat pengajuan tuntutan yang kadang-kadang miskin dari tela'ah potensi apalagi kajian dan solusi yang memadai (Daulay, 2007). Dengan demikian, agar proses menjalankan reformasi sesuai dengan tujuan yang diharakan, maka masyarakat harus tahu dan paham akan pengertian reformasi sebagai bekal yang kondusif dalam melakukan gerakan reformasi,

Reformasi dapat difahami sebagai upaya untuk mengembalikan hal-hal yang menyimpang kepada bentuk yang sesuai dengan konstitusi dan nilai-nilai ideal yang dicita-citakan rakyat. Dengan demikian menurut Syarbaini (2006), gerakan reformasi harus menyatu dengan kerangka Pancasila, sehingga paradigma reformasi berwujud suatu gerakan yang: 1) berdasarkan pada moralitas ketuhanan dan harus mengarah pada kehidupan yang baik sebgai manusia makhluk Tuhan, 2) berlandaskan pada moral kemanusiaan sebagai upaya penataan kehidupan yang penuh penghargaan atas harkat dan martabat manusia, 3) menjamin tetap tegaknya negara dan bangsa Indonesia sebagai satu kesatuan, 4) seluruh penyelenggaraan kehidupan berbangsa dan bernegara harus dapat menempatkan rakyat sebagai subjek dan pemegang kedaulatan dan 5) bertujuan pada keadilan sosial bagi seluruh rakyat Indonesia. Artinya, gerakan reformasi harus memiliki visi yang jelas, yaitu demi terwujudnya keadilan sosial bagi seluruh rakyat.

Gerakan reformasi harus dilanjutkan karena ranah pembentukan jiwa dan kepribadian yang diamanatkan oleh Pancasila belum menyentuh sasaran. Kondisi ini terlihat dari semakin maraknya koruptor melakukan aktivitas dengan frekwensi yang semakin meningkat, modus yang semakin beragam dan sasaran yang semakin bervariasi. Kondisi lain yang terlihat bahwa pemahaman terhadap Pancasila belum utuh dan menyeluruh sehingga ada kelompok yang ingin menafsirkan menurut pemahamannya masing-masing dan ada pula yang mencoba membuat dikotomi Pancasila dengan Agama. Kondisi ini tersebar pada semua lapisan masyarakat dengan variasi yang sangat beragam termasuk segelintir enyelenggara negara. Gerakan reformasi ditandai awalnya dengan trauma akibat penerapan Pancasila di masa Orde Baru, sehingga semua yang berbau Orde Baru diupayakan agar tidak digunakan misalnya GBHN, sebagai Landasan Operasional Pembangunan Nasional, penamaan Mata Kuliah Pembentuk Kepribadian di Perguruan Tinggi yang awalnya Pendidikan Kewiraan menjadi Pendidikan Kewarganegaraan dan sebagainya.

\section{Meluruskan Pemahaman Pancasila Untuk Mencapai Tujuan Nasional Bangsa Indonesia}

Pancasila adalah penuntun kehidupan bersama dalam berbangsa dan bernegara. Dengan memahami Pancasila dengan benar, maka Bangsa Indonesia akan mamu menghadapi segala bentuk hambatan, gangguan, tantangan dan ancaman terhadap kehidupan berbangsa dan bernegara, baik yang datang dari luar atau bersumber dari dalam. Pemahaman terhadap Pancasila harus dilakukan secra utuh oleh setiap komponen bangsa, agar Bangsa dan Negara Indonesia mampu mencapai Tujuan Nasional. Bagi Bangsa dan Negara Indonesia, dalam kehidupan berbangsa dan bernegara, Pancasila berperan sebagai:

\section{Dasar Negara}

Pancasila adalah sumber dari segala sumber hukum negara. Dengan demikian, maka segala sesuatu yang berhubungan dengan kehidupan ketatanegaraan RI harus didasarkan pada Pancasila yang memuat seluruh peraturan yang berlaku di Indonesia. Segala peraturan perundang-undangan yang berlaku di Indonesia harus 
diambil dari Pancasila atau tidak bertentangan dengan Pancasila Daulay, 2007; Maryani, 2014).

\section{Ideologi Negara}

Pancasila adalah sumber idea dan gagasan untuk mencapai Tujuan Nasional. Ideologi negara akan mempengaruhi karakter, identitas dan pola hubnngan Bangsa dan Negara dalam menjalin hubungan secara internasional (Sulistyo, 2010). Oleh karena itu semua komponen Bangsa berkewajiban menjaga Pancasila agar tidak disusupi oleh ideologi asing bahkan yang bertentangan dengan Pancasila.

\section{Pandangan Hidup Bangsa}

Dalam kehidupan berbangsa dan bernegara, diperlukan kerangka acuan untuk menata kehidupan pribadi serta melakukan interaksi antar manusia di dalam masyarakat dan alam sekitarnya. Inilah yang disebut dengan pandangan hidup bangsa (Novariyanti, 2014). Pandangan hidup bangsa juga digunakan sebagai panutan dan petunjuk arah bagi bangsa dalam setiap kegiatan, aktivitas dan kehidupan di segala bidang. Pandangan hidup mengandung nilai-nilai luhur yang membentuk wawasan menyeluruh terhadap kehidupan bersama dalam NKRI tercinta.

\section{Jiwa dan Kepribadian Bangsa Indonesia}

Pancasila telah menjadi jiwa bangsa Indonesia jauh sebelum Bangsa Indonesia memproklamirkan kemerdekaannya. Nilai-nilai Pancasila telah diyakini kebenarannya, oleh karena itu Bangsa Indonesia bertekad untuk mewujudkannya dalam sikap dan tingkah laku (Katimin 2010, Maryani, 2014; Novariyanti, 2014). Dengan demikian, Pancasila bukanlah merupakan pemikiran perorangan melainkan suatu bentuk gambaran kehidupan sehari-hari baik sebagai pandangan hidup bangsa yang telah permanen tertanam dalam pribadi setiap orang di Indonesia.

\section{Pemersatu Bangsa}

Bangsa Indonesia adalah bangsa yang sangat beragam dalam segala bidang baik fisik maupun non fisik. Keberagaman ini memerlukan alat pemersatu, sesuatu yang diyakini sama kebenarannya oleh semua pihak. Menurut Amir (2003) dan Sulistyo (2010), Pancasila yang mengandung nilai-nilai yang berasal dari jiwa dan tmmbuh serta berkembang bersama Bangsa Indonesia sebagai buah renungan mendalam adalah alat pemersatu yang tepat bagi Bangsa Indonesia.

\section{Perjanjian Luhur}

Perjanjian luhur adalah kesepakatan para leluhur pejuang bangsa. Menurut Taufik (2013), Pancasila telah disepakati secara Nasional oleh para pejuang kemerdekaan Indonesia Tanggal 18 Agustus 1945 melalui sidang PPKI Pertama (Panitia Persiapan Kemerdekaan Indonesia). sebagai dasar Negara.
Tujuan Nasional Bangsa Indonesia dicantumkan pada alinea ke 4 Pembukaan UUD 1945 yaitu: 1) Melindungi segenap bangsa Indonesia dan seluruh tumpah darah Indonesia 2) Memajukan kesejahteraan umum 3) Mencerdaskan kehidupan bangsa dan 4) Ikut melaksanakan ketertiban dunia yang berdasarkan kemerdekaan, perdamaian abadi dan keadilan sosial (Syarbaini, 2003; Novariyanti, 2014). Ke 4 Tujuan Nasional tersebut saling berkaitan serta saling mempengaruhi satu dengan yang lain. Oleh karena itu diharapkan dalam kehidupan berbangsa dan bernegara, ke 4 tujuan itu dapat dicapai secara simultan, bertahap dan berkelanjutan. Pencapaian Tujuan Nasional sangat dimungkinkan melalui emahaman yang benar terhadap Pancasila oleh semua komponen bangsa.

\section{SIMPULAN}

1. Bangsa Indonesia dapat dinyatakan sebagai kausa materialis karena telah memiliki milai-nilai Pancasila dalam kehidupannya sebelum terbentuknya Negara Indonesia.

2. Dalam perjalanan sejarah Bangsa Indonesia terlihat bahwa masih banyak kelemahan dan penyimpangan dalam penerapan Pancasila. Kondisi ini harus mendapat perhatian yang cermat oleh seluruh komponen bangsa agar sesuai dengan perjanjian luhur yang telah disepakati sejak awal pendirian negara ini.

3. Untuk mencapai hal itu diperlukan pemahaman yang utuh dan menyeluruh terhadap Pancasila oleh seluruh komponen bangsa.

\section{DAFTAR PUSTAKA}

Amir, Zainal Abidin. 2003. Peta Islam politik Pasca Soeharto. LP3ES. Jakarta.

Daulay, Haidar Putra. 2007. Sejarah pertumbuhan dan pembaharuan pendidikan Islam di Indonesia. Kencana. Jakarta

Katimin. 2010. Politik dan masyarakat pluralis. Cita Pustaka Media. Jakarta.

Maryani. 2014. Pancasila masa Orde Lama. http://manusiabayangansaidi9.blogspot.com/ 2014/06/Pancasila-masa-orde-lama.html?m=1

Noviriyanti. 2014. Ringkasan tentang Pancasila Era Reformasi._https://noviriyanti.wordpress. com/2014/08/22/ringkasan-tentang-Pancasila-erareformasi/

Syarbaini, Syahrial. 2003. Pendidikan Pancasila di Perguruan Tinggi. Ghalia. Jakarta

Syarbaini, Syahrial. 2006. Membangun karakter dan Kepribadian melalui Pendidikan Kewarganegaraan. Graha Ilmu. Yogyakarta

Sulistyo, A. 2010. Pancasila di masa Orde Baru. https://www.kompasiana.com/andisulistyo/ 55105d69a333117b39ba8034/Pancasila-di-masaorde-baru 
Taufik. 2013. Perjalanan sejarah Pancasila dari lahir. http://taufik-oriwe.blogspot.com/2013/02/ perjalanan-sejarah-Pancasila-dari-lahir.html? $\mathrm{m}=1$

Thohir, Ajib. 2009. Perkembangan peradaban di kawasan Dunia Islam, melacak akar-akar sejarah, sosial, politik dan budaya Umat Islam. Rajawali Pers. Jakarta.

V.Wiratna Sujarweni, 2014. Metodeologi Penelitian. Yogyakarta: Pustaka Baru Perss 